\title{
Estimation of crossbreeding parameters between Large White and Meishan porcine breeds. III. Dominance and epistatic components of heterosis on reproductive traits
}

\author{
JP Bidanel \\ INRA, Station de Génétique Quantitative et Appliquée, \\ Centre de Recherches de Jouy-en-Josas, \\ 78352 Jouy-en-Josas Cedex, France
}

(Received 31 July 1991; accepted 20 January 1993)

\begin{abstract}
Summary - A crossbreeding experiment using Large White (LW) and Meishan (MS) pig strains was conducted. Dominance, additive $\times$ additive and dominance $\times$ dominance epistatic components of direct and maternal heterosis effects were investigated for various litter productivity and sow traits: total number born (TNB), number born alive (NBA), number weaned (NW), litter weight at birth (LWB) and at $21 \mathrm{~d}$ (LW21), either adjusted or not for litter size, sow weight loss (SWL), sow total (SFC) and maximum (SFCM) feed consumption, sow feed efficiency - computed as SFC per piglet weaned (SFC/NW) or per unit of litter weight gain (SFC/LWG) - during lactation. Data from 1148 litters farrowed by 250 sows were analysed. Models involving all possible combinations of dominance and epistatic parameters were compared for goodness of fit on the basis of their mean squared error (MSE). The model with the lowest MSE was then used to estimate crossbreeding parameters. Models involving dominance effects only for maternal heterosis had the lowest MSE for all litter productivity traits. Dominance also appeared as the main component of direct heterosis effects on litter productivity traits. Favourable dominance and unfavourable epistatic effects contributed to direct heterosis effects for all sow traits except SFCM. Epistatic effects were additive $\times$ additive effects for SFC/NW and dominance $x$ dominance effects for SWL, SFC and SFC/LWG. Estimates of direct, maternal and grand-maternal breed effects are presented. A possible contribution of cytoplasmic effects to between-breed variation is also hypothesized.
\end{abstract}

pig / Chinese breed / reproductive trait / dominance / epistasis

Résumé - Estimation des paramètres du croisement entre les races porcines Large White et Meishan. 3. Composantes de dominance et d'épistasie des effets d'hétérosis pour les caractères de reproduction. Une expérience de croisement entre des lignées porcines Large White (LW) et Meishan (MS) a été réalisée. Les composantes de dominance 
et d'épistasie additive $\times$ additive et de dominance $\times$ dominance des effets d'hétérosis direct et maternel ont été estimées pour divers caractères de productivité de la portée et de la truie: nombre de porcelets nés totaux (NT), nés vivants (NV), sevrés (NS), poids de la portée à la naissance (PPN) et à $21 j$ (PP21), ajustés ou non pour la taille de la portée, perte de poids (PPT), consommation totale (CAT) et maximale (CAM), efficacité alimentaire - calculée comme CAT par porcelet sevré (CAT/NS) et CAT par unité de gain de poids de la portée (CAT/GPP) - de la truie en lactation. Les analyses ont porté sur 1148 portées issues de 250 truies. La validité de l'ajustement des modèles incluant l'ensemble des combinaisons possibles des paramètres de dominance et d'épistasie est comparée sur la base du carré moyen de l'erreur (CME). Le modèle ayant le plus faible $C M E$ a ensuite été utilisé pour estimer les paramètres du croisement. Les modèles incluant uniquement des effets de dominance pour l'hétérosis maternel avaient le CME le plus faible pour l'ensemble des caractères de productivité de la portée. Les effets de dominance sont également apparus comme la principale composante de l'hétérosis direct pour les caractères de productivité de la portée. Des effets de dominance favorables et d'épistasie défavorables contribuent aux effets d'hétérosis direct pour l'ensemble des caractères de productivité des truies, sauf CAM. Les effets d'épistasie sont de type additif $\times$ additif pour $C A T / N S$ et de dominance $\times$ dominance pour PPT, CAT et CAT/GPP. Des estimations des différences directes, maternelles et grand-maternelles entre races sont présentées. L'hypothèse d'une contribution possible d'effets cytoplasmiques à la variation entre races est émise.

porcin/ race chinoise / caractères de reproduction / dominance / épistasie

\section{INTRODUCTION}

A limited number of native pig breeds from China, such as the Meishan breed, exhibit exceptional reproductive ability with respect to currently used maternal genotypes and could be of great interest for improving sow productivity in maternal lines (Legault and Caritez, 1983). Their economic value can easily be assessed using an analytical approach such as those developed by Dickerson $(1969,1973)$ or more recently Kinghorn (1980), Hill (1982) and Koch et al (1985), based on partitioning between-breed variation into its additive and nonadditive components. The corresponding parameters, usually referred to as crossbreeding parameters, are then very useful for predicting the average performance of crossbred genotypes.

Bidanel et al $(1989,1990)$ estimated breed additive and heterosis effects relative to the cross between the Meishan and the most widely used French breed, the Large White, for reproductive and growth traits. This set of parameters allows an accurate prediction of the average performance of the first generations of crossing. It can also be used for later generations if heterosis is solely due to dominance gene effects. In that case, the amount of heterosis retained in later generations is linearly related to heterozygosity (McGloughlin, 1980). For instance, half of the heterosis expressed in $F_{1}$ crosses is retained in backcrosses and $F_{2}, F_{3}, \ldots, F_{n}$ crosses. On the other hand, when nonallelic interactions are important, favourable within-breed epistatic combinations will partly be lost in advanced crosses because of random recombination of nonallelic genes. Predictions based on a simple dominance model of heterosis may then be strongly biased upwards. It is therefore of great importance to check for the existence of any epistatic effects before making such predictions. 
The objective of this study was to estimate dominance and epistatic components of heterosis effects relative to the cross between Meishan and Large White breeds for reproductive traits. Other parameters, including breed additive effects, were also estimated.

\section{MATERIAL AND METHODS}

\section{Data and experimental design}

The data originate from a crossbreeding experiment between Large White (LW) and Meishan (MS) pig breeds which took place between 1983 and 1989 at the INRA experimental domain of Le Magneraud (Surgères, Charente-Maritime). The threestep design of the experiment was described in detail by Bidanel et al (1989). The first step was a complete 2-breed diallel, which led to the production of 4 genetic types of females (MS, LW $\times$ MS, MS $\times \mathrm{LW}, \mathrm{LW})$ and 3 genetic types of males (MS, LW, $F_{1}=\mathrm{LW} \times \mathrm{MS}$ or MS $\left.\times \mathrm{LW}\right)$. In the second step, females chosen at random within each of the above-mentioned genotypes were mated to randomly chosen MS, $F_{1}$ or LW boars and produced 12 genetic types of litters. In the third step, randomly chosen females from these 12 genotypes were inseminated with semen from Piétrain (PI) boars in 5 successive parities.

In the present study, data from 1148 litters belonging to the 24 genetic types produced in the second and third steps of the crossbreeding experiment were used to estimate dominance and epistatic components of heterosis on litter size, litter weight loss and feed consumption during lactation. The distribution of sows and litters according to genetic type is presented in table I.

Table I. Distribution of sows and litters by genetic type.

\begin{tabular}{lccccc}
\hline \multirow{2}{*}{ Genetic type } & \multicolumn{2}{c}{ Second step } & & \multicolumn{2}{c}{ Third step } \\
\cline { 2 - 3 } \cline { 5 - 6 } & Sows & Litters & & Sows & Litters \\
\hline MS & 60 & 148 & & 18 & 64 \\
MS $($ LW $\times$ MS $)$ & 9 & 21 & & 15 & 48 \\
MS $($ MS $\times$ LW $)$ & 9 & 21 & & 18 & 75 \\
$F_{1} \times$ MS & 13 & 28 & & 14 & 45 \\
LW $\times$ MS & 18 & 54 & & 13 & 51 \\
MS $\times$ LW & 8 & 18 & & 18 & 71 \\
$F_{1}($ LW $\times$ MS $)$ & 11 & 24 & & 13 & 50 \\
$F_{1}($ MS $\times$ LW $)$ & 8 & 23 & & 13 & 48 \\
LW $($ LW $\times$ MS $)$ & 22 & 51 & & 12 & 44 \\
LW $($ MS $\times$ LW $)$ & 10 & 25 & & 14 & 55 \\
$F_{1} \times$ LW & 6 & 17 & & 7 & 34 \\
LW & 48 & 84 & & 19 & 49 \\
\hline
\end{tabular}

${ }^{1}$ Litter genetic type for the second step; sow genetic type for the third step. LW: Large White MS: Meishan $F_{1}: \mathrm{LW} \times \mathrm{MS}$ or MS $\times \mathrm{LW}$. The sire breed is mentioned first. 


\section{Herd management}

The sow herd has been managed under a batch farrowing system. Each batch included a maximum number of 24 sows. With the exception of some LW gilts showing delayed puberty, young females were bred at the age of $32 \mathrm{wk}$, after a synchronisation treatment with a progestagen. In order to avoid any effect of this treatment on prolificacy, inseminations were not made on the induced oestrus, but on the following natural one. Females were inseminated twice at a 24-h interval. All females that did not conceive at first mating joined the subsequent farrowing batch where they had the opportunity to be mated once more.

Litters were born in individual farrowing crates. When necessary, some piglets could be moved to another crate within the first few $\mathrm{h}$ after farrowing. With very few exceptions, these procedures were practised within each genetic type. Creep feed was provided to piglets at $\approx 5 \mathrm{~d}$ of age. Weaning occurred at around $28 \mathrm{~d}$ post-farrowing.

A $16 \%$ crude protein and $3100 \mathrm{kcal} \mathrm{DE} / \mathrm{kg}$ diet was fed ad libitum to all sows during lactation and at the rate of $2-2.2 \mathrm{~kg}$ for MS, $2.2-2.5 \mathrm{~kg}$ for crossbred and $2.5-2.7 \mathrm{~kg}$ for LW during gestation. A $3-4-\mathrm{kg}$ forage complement (beetroots or alfalfa) was also given during gestation.

\section{Traits measured}

Thirteen traits were considered: total number of fully formed piglets born (TNB); numbers of piglets born alive (NBA); unadjusted (NW) or adjusted for TNB (ANW) number of piglets weaned per litter; unadjusted (WB and W21) and adjusted (AWB and AW21) litter weights at birth and at $21 \mathrm{~d}$, respectively; sow weight loss during lactation, computed as the difference between sow weights before farrowing and at weaning (SWL); sow feed consumption during lactation (SFC), adjusted to a 30-d period as explained by Bidanel et al (1989); sow maximum daily feed consumption during lactation (SFCM); ratios of sow feed consumption to number weaned (SFC/NW) or litter weight gain (SFC/LWG). These 2 latter traits were proposed by Bidanel et al (1989) for evaluating feed efficiency of the lactating sow.

\section{Statistical analyses}

As recently shown by Komender and Hoeschele (1989), the accuracy of crossbreeding parameters estimation can be increased by including the genetic relationships among individuals in the model, ie by using an animal model. When variances are known, the resulting set of equations can easily be solved using standard mixed model techniques (Henderson, 1984). When variances are not known, as in the present case, estimates of fixed effects can be obtained as backsolutions from a restricted maximum likelihood (REML) analysis (Patterson and Thompson, 1971) by replacing the unknown variances by their REML estimates. In the present study, variances were estimated using K Meyer's DFREML set of programs (Meyer, 1988, 1989). Estimation of fixed effects and hypothesis testing were then performed using the PEST package (Groeneveld and Kovac, 1990). 


\section{Estimation of genetic type marginal means}

The assumed model for estimating genetic type means was as follows:

$$
\mathbf{Y}=\mathbf{X} \beta+\mathbf{Z a}+\mathbf{W} \mathbf{c}+\mathbf{e}
$$

with

$$
\begin{gathered}
E(\mathbf{Y})=\mathbf{X} \beta \\
E\left[\begin{array}{l}
\mathbf{a} \\
\mathbf{c} \\
\mathbf{e}
\end{array}\right]=\left[\begin{array}{l}
\mathbf{0} \\
\mathbf{0} \\
\mathbf{0}
\end{array}\right] \text { and } \operatorname{var}\left[\begin{array}{l}
\mathbf{a} \\
\mathbf{c} \\
\mathbf{e}
\end{array}\right]=\left[\begin{array}{ccc}
\mathbf{A} \sigma_{a}^{2} & \mathbf{0} & \mathbf{0} \\
\mathbf{0} & \mathbf{I} \sigma_{c}^{2} & \mathbf{0} \\
\mathbf{0} & 0 & \mathbf{I} \sigma_{e}^{2}
\end{array}\right]
\end{gathered}
$$

Where:

$$
\begin{array}{ll}
\mathbf{Y} & =\text { vector of records } \\
\beta & =\text { vector of fixed effects } \\
\mathbf{a} & =\text { vector of random genetic effects of sows } \\
\mathbf{c} & =\text { vector of random permanent environmental effects } \\
\mathbf{e} & =\text { vector of random residual effects }
\end{array}
$$

$\mathbf{X}, \mathbf{Z}, \mathbf{W}=$ design matrices relating records to the appropriate fixed or random effects

A $\quad=$ numerator relationship matrix

I = identity matrix

$\sigma_{a}^{2}, \sigma_{c}^{2}, \sigma_{e}^{2}=$ additive genetic, permanent environmental and residual variances respectively.

$E, v a r=$ expectation and variance operators, respectively.

The fixed effects for estimating genetic type marginal means were farrowing batch ( 66 levels), litter genetic type ( 24 levels) and parity ( 5 levels). The interaction between genetic type and parity and the effect of individual Piétrain boars (in the third step of the experiment) were tested in preliminary analyses. They were not significant for any of the traits $(P>0.10)$ and were consequently discarded from final analyses. Two covariables, ie litter size at birth (for ANW and AWB) or at weaning (for AW21) and exact age at measurement, were added to the model when appropriate. Preliminary analyses indicated that regression coefficients did not differ $(P>0.10)$ according to the genetic type. Simple linear regressions were used for AW21, but a quadratic term was added for ANW and AWB.

The significance of contrasts between genetic type means was tested using the following $F$ statistics:

with

$$
\mathbf{S}=\mathbf{Q} / s \sigma_{e}^{2}
$$

$$
\begin{aligned}
\mathbf{Q} & =\left(\mathbf{K}^{\prime} \tilde{\beta}\right)^{\prime}\left(\mathbf{K}^{\prime} \mathbf{C}_{11} \mathbf{K}\right)^{-1}\left(\mathbf{K}^{\prime} \widetilde{\beta}\right) \\
\sigma_{e}^{2} & =\left(\mathbf{y}^{\prime} \mathbf{y}-\widetilde{\beta}^{\prime} \mathbf{X}^{\prime} \mathbf{y}-\widetilde{\mathbf{a}}^{\prime} \mathbf{Z}^{\prime} \mathbf{y}-\widetilde{\mathbf{c}}^{\prime} \mathbf{W}^{\prime} \mathbf{y}\right) /(\mathbf{n}-\mathbf{r})
\end{aligned}
$$

where $\mathbf{X}, \mathbf{Z}$ and $\mathbf{W}$ are the same as in [1], $\mathbf{K}^{\prime}$ is the vector of rank $s$ defining the contrast, $\mathbf{C}_{11}$ is the submatrix of the generalized inverse of the coefficient matrix of 
the mixed model equations corresponding to $\mathbf{X}^{\prime} \mathbf{X} ; \widetilde{\beta}$ is the generalized least squares solution for $\beta, \widetilde{\mathbf{a}}$ and $\widetilde{\mathbf{c}}$ are the BLUP of $\mathbf{a}$ and $\mathbf{c}$, respectively, $n$ is the number of records and $r$ the rank of $\mathbf{X}$. Under the null hypothesis that $\mathbf{K}^{\prime} \beta=0, \mathbf{S}$ has a central $F$ distribution with $s$ and $(n-r)$ degrees of freedom.

\section{Estimation of crossbreeding parameters}

Crossbreeding parameters can either be estimated from genetic type marginal means (provided that their variance - covariance matrix is available) or from multiple regression procedures (Komender and Hoeschele, 1989). The latter method was used in the present study. The model was the same as model [1], except that genetic type effects were replaced by their decomposition according to adequately parameterized crossbreeding parameters. Additive effects between breeds were partitioned as proposed by Dickerson $(1969,1973)$ into direct, maternal and grand-maternal effects. Direct and maternal nonadditive effects were partitioned as proposed by Hill (1982) into their dominance $\left(d^{0}\right.$ and $\left.d^{m}\right)$, additive $\times$ additive $\left(a a^{0}\right.$ and $\left.a a^{m}\right)$, additive $\times$ dominance $\left(a d^{0}\right.$ and $\left.a d^{m}\right)$ and dominance $\times$ dominance $\left(d d^{0}\right.$ and $\left.d d^{m}\right)$ epistatic components in a 2-locus model. The decomposition of the 24 genetic types of litters produced in the experiment according to the corresponding parameters is shown in table II. For sow traits, only the first 12 genotypes from table II have to be considered. This model is applicable under the following hypotheses: 1) traits are governed by unlinked loci ; 2) gametes are produced by random samples of purebred or crossbred parents and unite at random; 3) paternal heterosis, sexlinked, imprinting and cytoplasmic maternal effects are negligible; 4) epistatic effects of order higher than 2 are negligible.

In fact, not all of the above-mentioned parameters could be estimated simultaneously from the present experiment. The direct genetic effect of PI breed $\left(g_{P I}^{0}\right)$, PI $\times$ MS and PI $\times$ LW direct heterosis effects $\left(h_{P M}^{0}\right.$ and $h_{P L}^{0}$, respectively) were partly confounded. This problem was solved by replacing $g_{P I}^{0}, h_{P M}^{0}$ and $h_{P L}^{0}$ by the 2 following parameters:

$$
\begin{aligned}
\Delta h^{0} & =h_{P M}^{0}-h_{P L}^{0} \\
d_{P L} & =1 / 2 g_{P I}^{0}+h_{P L}^{0}
\end{aligned}
$$

$\Delta h^{0}$ represents the difference in direct heterosis effects between PI $\times$ MS and PI $\times \mathrm{LW}$ crosses; $d_{P L}$ is more difficult to interpret, as it includes both the direct effect of PI boars crossed with LW dams and the effect of the type of mating (artificial insemination vs natural mating). Hence, results for this parameter have little interest and will not be presented hereafter. Then, direct and maternal additive $\times$ dominance epistatic effects $\left(a d^{0}\right.$ and $\left.a d^{m}\right)$ were confounded with direct $\left(g^{0}\right)$ and maternal $\left(g^{m}\right)$ additive genetic effects, respectively. Finally, maternal nonadditive effects on sow traits could not be partitioned into their dominance and epistatic components, so that only maternal heterosis was estimated. Hence, the full model included either $g^{0}, g^{m}, g^{n}, d_{P L}, \Delta h^{0}, d^{0}, a a^{0}, d d^{0}, d^{m}, a a^{m}, d d^{m}$ (litter traits) or $g^{0}, g^{m}, g^{n}, d^{0}, a a^{0}, d d^{0}, h^{m}$ (sow traits).

The estimation process was performed as follows. The goodness of fit of all possible constrained models (obtained by deleting one or several of the abovementioned parameters) was first compared and tested with regard to the full model 


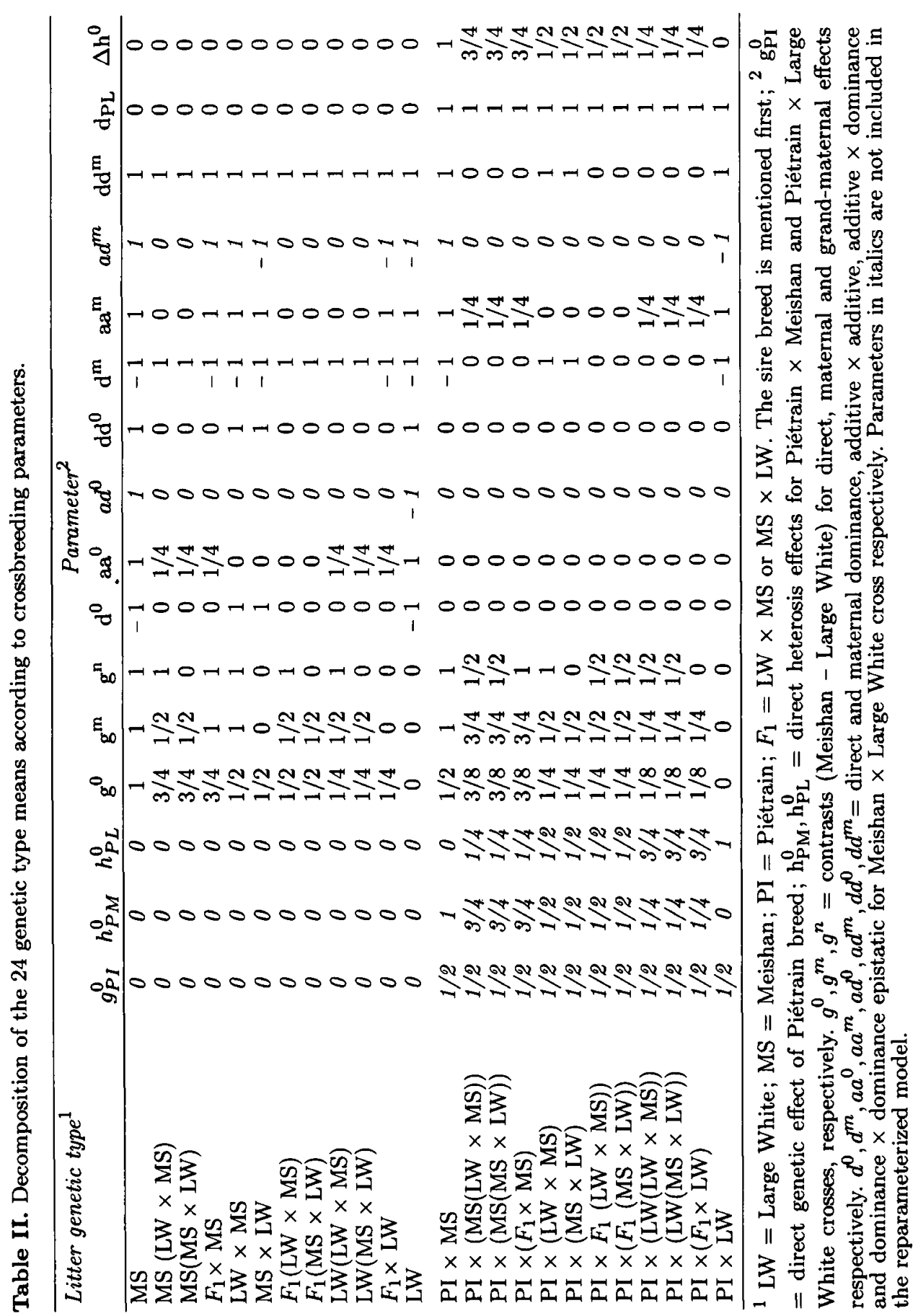


on the basis of their mean squared error (MSE) as proposed by Fimland (1983). A total of 49 and 7 models for litter and sow traits respectively, were investigated. The model with the lowest MSE was then considered as the best model for prediction and used to estimate the relevant crossbreeding parameters.

\section{RESULTS}

\section{Analyses of variance}

Litter size, sow feed consumption and efficiency traits showed significant batch effects, but without any consistent seasonal trend. Parity affected all traits except SWL. Its influence on litter weights and sow feed consumption and efficiency followed a similar pattern. No significant difference appeared from the 2nd to the 5th parity, whereas first parity gilts had lighter litters $(-2.7 \mathrm{~kg}$ and $-10 \mathrm{~kg}$ at birth and $21 \mathrm{~d}$ respectively), consumed less feed $(-22 \mathrm{~kg})$ and had a better feed efficiency $(-1.6 \mathrm{~kg}$ feed / piglet and $-0.11 \mathrm{~kg}$ feed / $\mathrm{kg}$ LWG) during lactation than multiparous sows. Conversely, litter size at birth was constant over the first 2 parities and then steadily increased $(+0.8 ;+1.3$ and +1.5 piglet / litter for the 3rd, 4th and 5th parities respectively). At weaning, litter size increased linearly up to the 3rd parity, then plateaued (NW) or decreased (ANW).

The effect of genetic type was highly significant for all traits. Genetic type means for litter traits in the second step of the experiment were rather similar to those previously obtained by Bidanel et al (1989) in a first analysis of a subsample of this second step. Hence, they will not be presented here again. Estimates of genetic type means for litter traits in the third step of the experiment are presented in table III. $F_{1}, \mathrm{MS}(\mathrm{LW} \times \mathrm{MS})$ and $F_{1}(\mathrm{LW} \times \mathrm{MS})$ had the largest litters at birth. On average, they farrowed 1.2 piglets more per litter than an intermediate group including MS, MS(MS $\times$ LW), LW(MS $\times$ LW) and $F_{1} \times \mathrm{MS}, 2.5$ piglets more than $F_{1}(\mathrm{MS} \times$ $\mathrm{LW}), \mathrm{LW}(\mathrm{MS} \times \mathrm{LW})$ or $F_{1} \times \mathrm{LW}$ and $3.4(\mathrm{TNB})$ to $4.3(\mathrm{NBA})$ piglets more than LW. These differences remained similar for UNW, but were reduced after adjusting the data for TNB. Genetic types ranked almost the same as at birth, except that MS(MS $\times$ LW $)$ and LW(LW $\times$ MS) joined the prolific group. Females born to MS $\times \mathrm{LW}$ dams tended to have a better prolificacy than those born to MS $\times$ LW. The difference was significant $(P<0.05)$ for $F_{2}$ and $3 / 4 \mathrm{LW}$ females, but not for $3 / 4 \mathrm{MS}$.

$F_{1}$ sows and to a lesser extent $F_{1}(\mathrm{LW} \times \mathrm{MS})$ had the heaviest litters at birth and at $21 \mathrm{~d}$, with a mean advantage of $1.2 \mathrm{~kg}$ (WB) and $6.0 \mathrm{~kg}$ (W21) over a group including MS $(\mathrm{LW} \times \mathrm{MS}), \mathrm{MS}(\mathrm{MS} \times \mathrm{LW})$ and $\mathrm{LW}(\mathrm{LW} \times \mathrm{MS})$. The other genetic types except LW had similar WB (from 13.0 to $13.9 \mathrm{~kg}$ ), but more variable W21 (from $43.5 \mathrm{~kg}$ for MS to $53.5 \mathrm{~kg}$ for LW(MS $\times \mathrm{LW})$ ). LW had the lightest litters at birth, but its average W21 was comparable to $F_{1}$ sired dams and superior to MS. Adjusting the data for litter size reduced the amount of variation between genetic types and led to some changes in their ranking. $F_{1}, 3 / 4 \mathrm{LW}$ and $\mathrm{LW}$ had similar AWB and were $1 \mathrm{~kg}$ heavier than $F_{2}$ or $3 / 4 \mathrm{MS}$, except $F_{1} \times \mathrm{LW}$ which were close to MS. MS $\times$ LW had the heaviest AW21, with an advantage of $\approx 5 \mathrm{~kg}$ over LW, $3 / 4 \mathrm{LW}, F_{2}$ and $\mathrm{LW} \times \mathrm{MS}$, of $9 \mathrm{~kg}$ over $3 / 4 \mathrm{MS}$ and of $18 \mathrm{~kg}$ over MS.

Estimates of genetic type means for sow traits are presented in table IV. MS sows lost much less weight from farrowing to weaning than the other genetic types: 


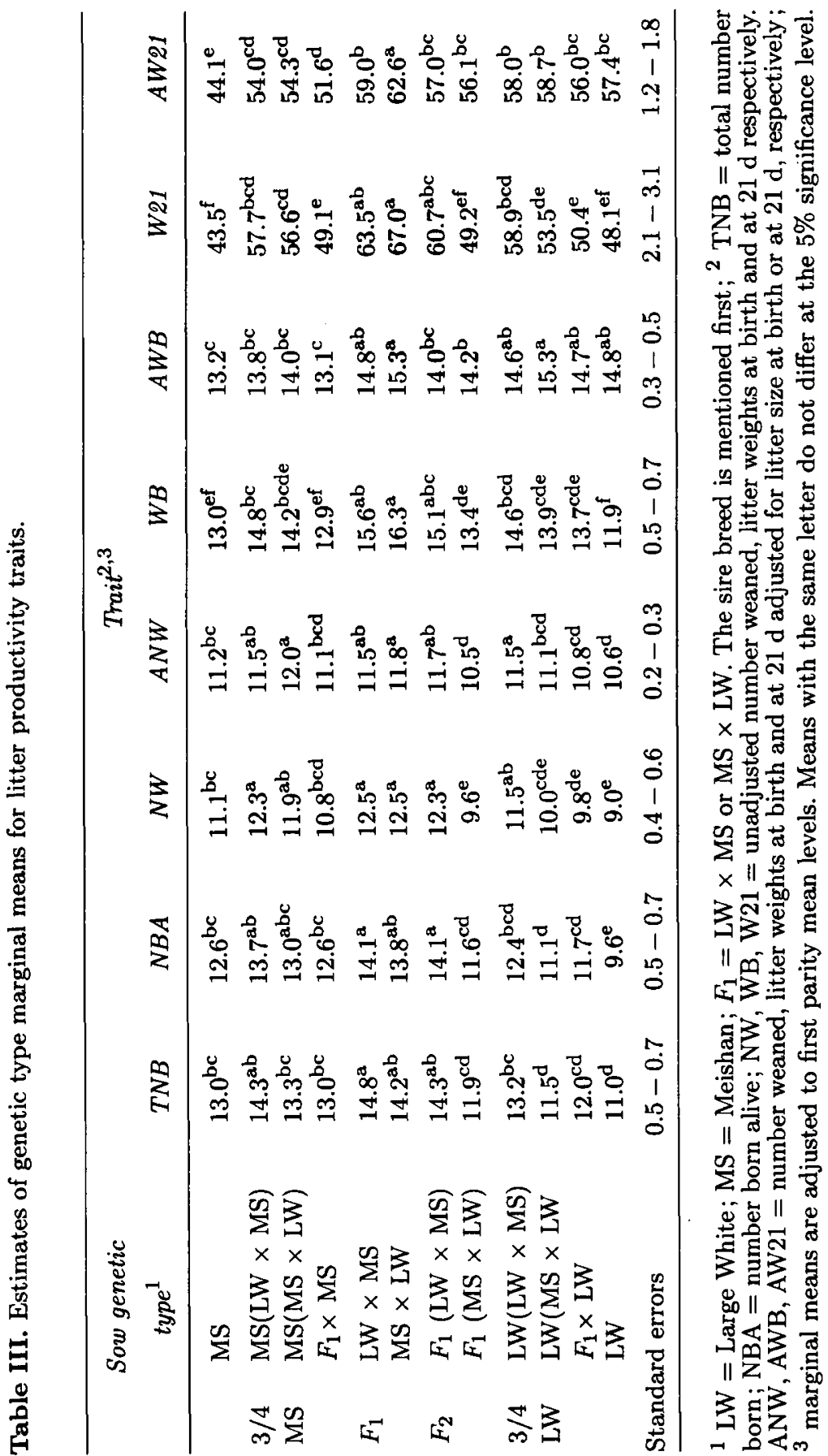


$17 \mathrm{KG}$ less than in $F_{1}, 10-12 \mathrm{~kg}$ less than in LW, LW $\times F_{1}, F_{1}(\mathrm{LW} \times \mathrm{MS})$ or $\mathrm{MS}(\mathrm{LW} \times \mathrm{MS})$ and $5-7 \mathrm{~kg}$ less than in remaining genotypes. MS also consumed about $25 \mathrm{~kg}$ less feed during lactation than $\mathrm{LW}, F_{1}, F_{2}$, or $3 / 4 \mathrm{LW}$ (except $F_{1} \times$ LW) and $17 \mathrm{~kg}$ less than $3 / 4 \mathrm{MS}$ of $F_{1} \times \mathrm{LW}$. As a consequence, MS had the highest feed efficiency per piglet weaned (SFC/NW). On average, feed consumption per piglet increased with increasing proportions of LW genes. On the other hand, feed consumption per unit of litter weight gain (SFC/LWG) did not differ much between purebreeds, but was lower in most crossbred sows, especially $F_{1}$ sows.

Table IV. Estimates of genetic type marginal means for sow weight loss, feed consumption and efficiency during lactation.

\begin{tabular}{|c|c|c|c|c|c|c|}
\hline \multicolumn{2}{|r|}{$\begin{array}{c}\text { Sow genetic } \\
\text { type }^{1}\end{array}$} & $S W L$ & \multicolumn{3}{|c|}{ Trait $^{2,3}$} & $S F C / L W G$ \\
\hline & MS & $35.2^{f}$ & $108^{d}$ & $4.8^{\mathrm{e}}$ & $10.4^{e}$ & $3.41^{\mathrm{ab}}$ \\
\hline $3 / 4$ & $\mathrm{MS}(\mathrm{LW} \times \mathrm{MS})$ & $46.0^{\mathrm{cd}}$ & $124^{\mathrm{c}}$ & $5.3^{\mathrm{cd}}$ & $10.3^{e}$ & $2.73^{\mathrm{cd}}$ \\
\hline MS & $\begin{array}{l}\mathrm{MS}(\mathrm{MS} \times \mathrm{LW}) \\
F_{1} \times \mathrm{MS}\end{array}$ & $\begin{array}{l}40.5^{\mathrm{e}} \\
39.7^{\mathrm{ef}}\end{array}$ & $\begin{array}{l}129^{\mathrm{bc}} \\
123^{\mathrm{c}}\end{array}$ & $\begin{array}{l}5.6^{\mathrm{bcd}} \\
5.4^{\mathrm{cd}}\end{array}$ & $\begin{array}{l}11.4^{\mathrm{de}} \\
12.2^{\mathrm{cd}}\end{array}$ & $\begin{array}{l}2.88^{\mathrm{cd}} \\
3.38^{\mathrm{ab}}\end{array}$ \\
\hline$F_{1}$ & $\begin{array}{l}\mathrm{LW} \times \mathrm{MS} \\
\mathrm{MS} \times \mathrm{LW}\end{array}$ & $\begin{array}{l}51.7^{\mathrm{ab}} \\
53.1^{\mathrm{a}}\end{array}$ & $\begin{array}{l}133^{\mathrm{ab}} \\
132^{\mathrm{abc}}\end{array}$ & $\begin{array}{l}5.8^{\mathrm{abc}} \\
5.7^{\mathrm{abc}}\end{array}$ & $\begin{array}{l}10.7^{\mathrm{de}} \\
11.4^{\mathrm{de}}\end{array}$ & $\begin{array}{l}2.56^{\mathrm{d}} \\
2.48^{\mathrm{d}}\end{array}$ \\
\hline$F_{2}$ & $\begin{array}{l}F_{1}(\mathrm{LW} \times \mathrm{MS}) \\
F_{1}(\mathrm{MS} \times \mathrm{LW})\end{array}$ & $\begin{array}{l}47.5^{\mathrm{bc}} \\
41.5^{\mathrm{de}}\end{array}$ & $\begin{array}{l}132^{\mathrm{abc}} \\
132^{\mathrm{abc}}\end{array}$ & $\begin{array}{l}5.8^{\mathrm{abc}} \\
5.7^{\mathrm{ab}}\end{array}$ & $\begin{array}{l}11.6^{\mathrm{de}} \\
14.5^{\mathrm{ab}}\end{array}$ & $\begin{array}{l}2.75^{\mathrm{cd}} \\
3.60^{\mathrm{a}}\end{array}$ \\
\hline $\begin{array}{l}3 / 4 \\
\text { LW }\end{array}$ & $\begin{array}{l}\mathrm{LW}(\mathrm{LW} \times \mathrm{MS}) \\
\mathrm{LW}(\mathrm{MS} \times \mathrm{LW} \\
F_{1} \times \mathrm{LW}\end{array}$ & $\begin{array}{l}48.3^{\mathrm{abc}} \\
48.4^{\mathrm{abc}} \\
42.6^{\mathrm{cde}}\end{array}$ & $\begin{array}{l}140^{\mathrm{a}} \\
134^{\mathrm{ab}} \\
123^{\mathrm{c}}\end{array}$ & $\begin{array}{l}6.1^{\mathrm{a}} \\
5.7^{\mathrm{abc}} \\
5.2^{\mathrm{de}}\end{array}$ & $\begin{array}{l}13.6^{\mathrm{bc}} \\
14.1^{\mathrm{ab}} \\
13.4^{\mathrm{bc}}\end{array}$ & $\begin{array}{l}3.22^{\mathrm{bc}} \\
3.16^{\mathrm{bc}} \\
3.34^{\mathrm{ab}}\end{array}$ \\
\hline Stan & $\begin{array}{l}\mathrm{LW} \\
\text { ard errors }\end{array}$ & $\begin{array}{l}45.8^{\mathrm{cd}} \\
1.9-2.7\end{array}$ & $\begin{array}{c}130^{\mathrm{abc}} \\
3.1-4.5\end{array}$ & $\begin{array}{c}5.4^{\mathrm{bcd}} \\
0.1-0.2\end{array}$ & $\begin{array}{c}15.5^{\mathrm{a}} \\
0.6-0.8\end{array}$ & $\begin{array}{c}3.41^{\mathrm{ab}} \\
0.14-0.20\end{array}$ \\
\hline
\end{tabular}

${ }^{1} \mathrm{LW}=$ Large White MS $=$ Meishan $; F_{1}=\mathrm{LW} \times \mathrm{MS}$ or MS $\times \mathrm{LW}$. The sire breed is mentioned first $;{ }^{2}$ SWL $=$ sow weight loss between farrowing and weaning; SFC, SFCM $=$ total and daily maximum sow feed consumption during lactation respectively; SFC/NW $=$ sow feed consumption per piglet weaned; SFC/LWG = sow feed consumption per unit of litter weight gain; ${ }^{3}$ marginal means are adjusted to first parity mean levels. Means with the same letter do not differ at the $5 \%$ significance level.

\section{Crossbreeding parameters}

The simple dominance model ( $i e$ with $d^{0}$ and $d^{m}$ only) had the lowest mean squared error (MSE) for all litter traits. Conversely, the best model for all sow traits except SFCM included either additive $\times$ additive or dominance $\times$ dominance epistatic effects. It should also be noted that in most cases several models had rather similar MSE, so that 7 to 20 models (litter traits) and 2 to 4 models (sow traits) could not 
be rejected at the $5 \%$ significance level. However, models without $d^{0}$ and $d^{m}$ were generally rejected.

Crossbreeding parameters for litter traits ar given in table V. Breed differences for prolificacy were essentially of maternal origin and in favour of MS. Conversely, significant $(P<0.05)$ direct breed effects in favour of $\mathrm{LW}$ were obtained for litter weight traits except W21. Maternal breed differences were nonsignificant for WB and W21, but were largely in favour of LW for AWB and AW21. Grand-maternal effects were of little importance for all traits except AW21. Differences between Piétrain $\times$ Meishan and Piétrain $\times$ Large White heterosis effects $\left(\Delta h^{0}\right)$ were slightly negative for litter size and slightly positive for litter weights, but none of the estimates approached significance. Direct dominance effects $\left(d^{0}\right)$ on litter size were close to zero at birth and were positive at weaning $(P<0.10$ for NW; $P<0.01$ for ANW). Estimates of $d^{0}$ were positive for all litter weights. All litter traits also exhibited highly positive, $i e$ favourable, maternal dominance effects $(P<0.001)$. Crossbreeding parameters for sow traits are shown in table VI. Additive effects on SFC, SFCM and, to a lesser extent, SWL were mainly of direct origin. MS genes were associated with lower weight loss and feed consumption during lactation. Direct effects were also the most important source of variation for breed efficiency traits, though significant maternal (and even grand-maternal) effects were obtained. Direct and grand-maternal effects were in favour of MS, whereas maternal effects were in favour of LW. All traits exhibited significant favourable direct dominance effects. Epistatic effects were significant for SFC/NW $(P<0.05)$, SWL and SFC/LWG $(P<0.05)$ and of the same sign as dominance effects, ie were unfavourable. Maternal dominance effects were favourable but nonsignificant, except for SFC and SFCM $(P<0.10)$.

\section{DISCUSSION}

The modelling of between-breed nonadditive effects has given rise to an important and somewhat controversial literature over the last $10 \mathrm{yr}$ (Kinghorn, 1980; Sedcole, 1981; Sheridan, 1981; Hill, 1982; Willham and Pollak, 1985; Eisen, 1989). Alternative models to the widely used Dickerson $(1969 ; 1973)$ decomposition of between-breed variability have been suggested. Sheridan (1981) proposed a 'parental epistatic' model. Each parental line is homozygous for different pairs of complementary genes which act additively with other pairs. Kinghorn (1980, 1982) compared different epistatic models differing in the type of gene action. However, the most general and satisfactory model, based on Cockerham's (1954) decomposition of genetic variance in a 2-locus model, was proposed by Hill (1982). Later, Koch et al (1985) partly extended Hill's model to include maternal effects. However, they included only additive $x$ additive interactions. Hill's model was preferred to Dickerson's model because of its greater generality. Indeed, it can be shown that Dickerson's model is equivalent to Hill's model when dominance $\times$ dominance effects are assumed to be 0 and that, in that case, the following relationships hold (Koch et al, 1985):

$$
\begin{aligned}
& h=2 \times d-a a \\
& r=-a a
\end{aligned}
$$




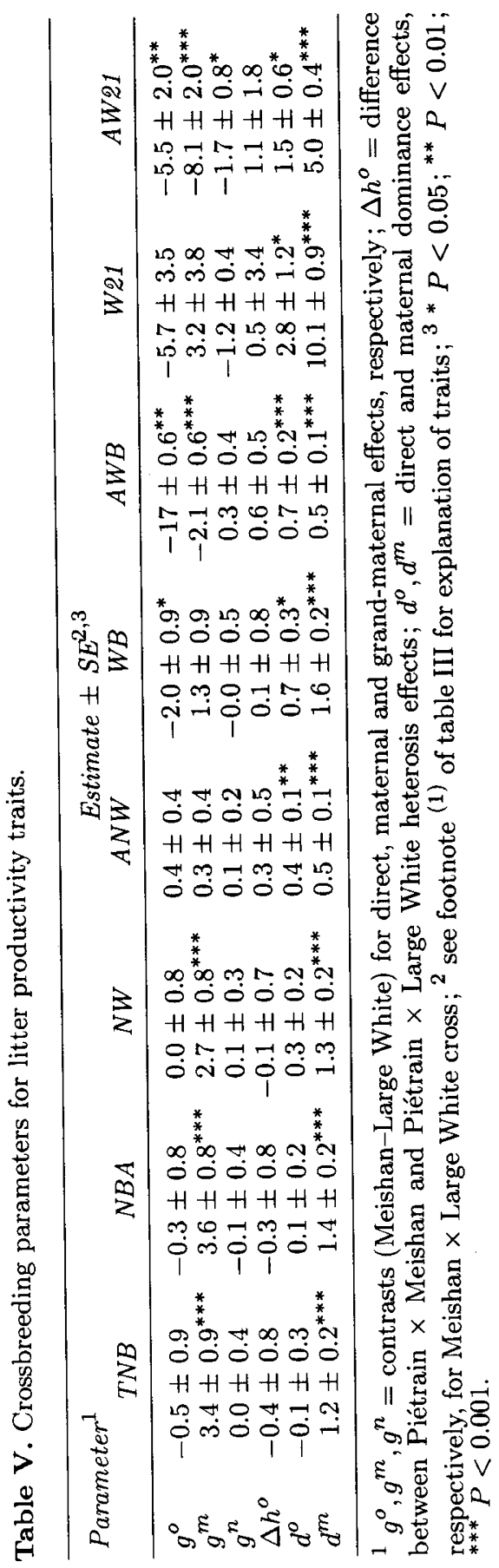


Table VI. Crossbreeding parameters for sow weight loss, feed consumption and efficiency during lactation.

\begin{tabular}{lccccc}
\hline Parameter $^{1}$ & \multicolumn{5}{c}{ Estimate $\pm S E^{2,3}$} \\
& \multicolumn{1}{c}{$S W L$} & $S F C$ & SFCM & SFC/NW & SFC/LWG \\
\hline$g^{o}$ & $-6.0 \pm 3.8$ & $-28.9 \pm 5.0^{* * *}$ & $-1.20 \pm 0.20^{* * *}$ & $-6.3 \pm 1.0^{* * *}$ & $-0.64 \pm 0.25^{*}$ \\
$g^{m}$ & $-3.9 \pm 3.4$ & $1.4 \pm 4.8$ & $0.01 \pm 0.21$ & $1.7 \pm 0.8^{*}$ & $0.44 \pm 0.21^{*}$ \\
$g^{n}$ & $3.4 \pm 2.7$ & $0.4 \pm 3.8$ & $0.08 \pm 0.16$ & $-1.6 \pm 0.7^{*}$ & $-0.22 \pm 0.17$ \\
$d^{o}$ & $5.8 \pm 1.4^{* * *}$ & $7.0 \pm 2.2^{* *}$ & $0.33 \pm 0.11^{* *}$ & $-2.5 \pm 1.0^{*}$ & $-0.39 \pm 0.09^{* * *}$ \\
$a a^{o}$ & - & - & - & $-3.1 \pm 1.9^{+}$ & - \\
$d d^{o}$ & $5.1 \pm 2.6^{*}$ & $2.9 \pm 2.9$ & - & - & $-0.38 \pm 0.18^{*}$ \\
$d^{m}$ & $0.4 \pm 1.5$ & $3.6 \pm 1.8^{*}$ & $0.15 \pm 0.08^{+}$ & $-0.4 \pm 0.3$ & $-0.14 \pm 0.09$ \\
\hline
\end{tabular}

${ }^{1} g^{o}, g^{m}, g^{n}=$ contrasts (Meishan-Large White) for direct, maternal and grand-maternal effects, respectively; $d^{o}, d^{m}, a a^{o}, d d^{o}=$ direct dominance, maternal dominance, direct additive $x$ additive and dominant $x$ dominance epistatic effects for Meishan $x$ Large White cross, respectively; ${ }^{2}$ see footnote ${ }^{(1)}$ of table IV for explanation of traits; $3+P<0.10 ;{ }^{*} P<0.05 ;{ }^{* *} P<0.01 ;{ }^{* * *} P<0.001$.

Hence, Dickerson's model can be viewed as one possible submodel of Hill's general model. Consequently, as emphasized by Hill (1982), 'recombination loss' generally cannot be expressed as a function of $d, a a$ and $d d$ parameters. For instance, in the present case the estimation of $r^{0}$ involves 2 types of contrasts which have different expectations in terms of epistatic interactions:

$$
\begin{aligned}
\overline{B C}_{M}-\overline{F_{2}} & =1 / 4 r^{0}=-1 / 4 a a^{0} \\
2 \overline{B C}_{P}-\overline{F_{1}}-\bar{P} & =1 / 2 r^{0}=-1 / 2 a a^{0}-2 d d^{0}
\end{aligned}
$$

where $\bar{P}, \bar{F}_{1}, \bar{F}_{2}, \overline{B C}_{M}, \overline{B C}_{P}=$ average performance of purebreds, $F_{1}, F_{2}$, maternal and paternal backcrosses, respectively; $r^{0}, a a^{0}, d d^{0}=$ direct epistatic recombination loss, direct additive $\times$ additive and dominance $\times$ dominance epistatic effects, respectively.

Because of its generality and its consistency with within-breed decomposition of genetic variance, Hill's model appears as the model of choice from a theoretical viewpoint. However, it still has several limitations which should be pointed out. First of all, it is generally highly overparameterized. In some instances, it is of no importance for predicting the average performance of advanced generations of crossings. This is the case for additive $\times$ dominance effects which do not seem to be estimable when the model includes maternal effects. In other instances, some parameters have to be assumed negligible to make the model tractable. For example, several parameters are necessarily confounded when a general model including direct, maternal and paternal heterosis effects is used. In the present study, paternal nonadditive effects have been assumed to be zero. This appears as a quite reasonable hypothesis in pigs, as suggested by a now quite abundant amount of results (see reviews by Buchanan, 1987; or Bidanel, 1988). The number of nonestimable parameters also increases when more than 2 populations are involved and when interactions of order higher than 2 are considered. Other 
effects, such as interactions between direct and maternal nonadditive effects or heterosis $\times$ environment interactions which might be of some importance in pigs (see for instance Kennedy and Quinton, 1987), are not taken into account. These interactions might be alternative explanations for discrepancies between - performance of advanced generations of crossings and their expectation under the dominance model for heterosis. Unfortunately, they could not be investigated through the present experimental design.

As emphasized by Hill (1982) and Koch et al (1985), another important limitation of complex heterosis models stems from the difficulty of getting accurate estimates of parameters. Even large well-designed experiments have a limited ability to distinguish between different models for heterosis. For example, the basic estimable functions to estimate additive $\times$ additive and dominance $\times$ dominance effects are $4\left(\overline{B C}_{M}-\bar{F}_{2}\right)$ and $\left(\bar{P}+\bar{F}_{1}+\overline{2 F}_{2}-2 \overline{B C}_{M}-2 \overline{B C}_{P}\right)$, respectively $\left(\bar{P}, \bar{F}_{1}, \bar{F}_{2}, \overline{B C}_{M}, \overline{B C}_{P}=\right.$ average performance of purebreds, $F_{1}, F_{2}$, maternal and paternal backcrosses, respectively). Assuming no fixed effect, an equal sample size $n$ for each genotype and unrelated animals, the respective variances of $a a$ and $d d$ estimates are $32 \sigma^{2} / n$ and $14 \sigma^{2} / n$ where $\sigma^{2}$ is the within-genotype variance. Then, the respective number of observations per genotype required to show an effect of 0.5 piglet with a type I error rate of $5 \%$ and a power of $90 \%$ are as large as 14000 and 6500 . This is clearly the main reason why experimental studies of components of heterosis in animals are not very numerous. Some evidence of epistatic losses in egg production of chickens, in milk production of dairy cattle and in growth rate of beef cattle was reported in the review by Sheridan (1981). More recent evidence of epistatic effects has been provided by Kinghorn (1983) for various growth and reproductive traits in mice, by Koch et al (1985) for survival, pregnancy and marbling score in beef cattle, by Hagger $(1986 ; 1989)$ and Fairfull et al $(1987)$ for egg production and by Ericson and Danell (1986), Syrstad (1988) and Pedersen and Christensen (1989) for milk production in dairy cattle. Conversely, epistatic effects have been reported as negligible by Mc Gloughlin (1980) for reproductive traits in mice, Dillard et al (1980) and Koch et al (1985) for growth rate in beef cattle and Robinson et al (1981) for milk production in dairy cattle. Contrary to these species, there does not seem to be any report of significant epistatic effects in swine. Some indication of lower than expected prolificacy of $F_{2}$ or backcross sows has been reported by Sheridan (1981), but none of the epistatic loss estimates reached significance.

In spite of its limited power, the present experiment provides some information about the relative importance of dominance and epistatic components of heterosis for reproductive traits in swine. Significant epistatic losses were observed for sow weight loss and feed efficiency during lactation. These epistatic effects could be additive $x$ additive, but also dominance $x$ dominance interactions. Consequently, models considering only additive $\times$ additive epistatic, such as Dickerson's model, may be unsuitable to some animal breeding situations. However, dominance effects clearly appeared in most cases as the main component of both direct and maternal heterosis effects, even if in most cases the existence of epistatic effects of limited magnitude cannot be excluded.

An important practical question raised by the low power of the experiment aimed at estimating components of heterosis lies in the amount of bias due to using a 
wrong genetic model for prediction. Kinghorn and Vercoe (1989) concluded from a re-analysis of the data from Koch et al (1985) that in their study predictions were generally quite robust to differences in the genetic model used. As illustrated in table VII, this is not always the case. Some non-negligible differences between models were obtained: $1.6 \mathrm{~kg}$ feed / piglet weaned for the $\overline{F_{2}}-\bar{P}$ contrast on SFC/NW (ie $84 \%$ of heterosis value); $4.6 \mathrm{~kg}$ for the $\overline{R C}-\bar{P}$ contrast on SWL (ie $39 \%$ of heterosis value). As expected, the average absolute "bias" (average absolute deviation between predicted and observed values) noticeably increased when an important parameter, such as $d d^{0}$ for SWL, is ignored. It also increased when unimportant parameters were included in the model. The amount of bias is of course related to the precision of the estimation of crossbreeding parameters, which also depends on the model. It may therefore be crucial to choose the right model for prediction. In any case, it seems advisable to precisely evaluate the impact of the choice of the genetic model through sensitivity analyses (France and Thornley, 1984) when estimating crossbreeding parameters and when using these parameters to evaluate the relative merit of different crossbreeding systems.

Table VII. Predicted contrasts between 3 tested and 1 untested genotype and purebreds for 2 traits under 4 prediction models.

\begin{tabular}{|c|c|c|c|c|c|}
\hline \multirow[b]{2}{*}{ Model ${ }^{1}$} & \multicolumn{5}{|c|}{ Contrast $^{2}$} \\
\hline & $\overline{F_{1}}-\overline{\mathrm{P}}$ & $\overline{\mathrm{F}_{2}}-\overline{\mathrm{P}}$ & $\overline{\mathrm{BC}}-\overline{\mathrm{P}}$ & $\overline{\mathrm{RC}}-\overline{\mathrm{P}}$ & $|\overline{B i a s}|$ \\
\hline & \multicolumn{5}{|c|}{ Sow weight loss between farrowing and weaning } \\
\hline Observed difference & 11.8 & 4.0 & 5.3 & - & - \\
\hline$d^{o}, a a^{o}, d d^{o}$ & 11.7 & 0.8 & 2.0 & 4.1 & 2.2 \\
\hline$d^{o}, a a^{o}$ & 11.7 & 1.1 & 4.1 & 6.0 & 1.4 \\
\hline$d^{o}, d d^{o}$ & 11.6 & 2.9 & 2.9 & 4.0 & 1.2 \\
\hline \multirow[t]{2}{*}{$d^{o}$} & 11.8 & 7.1 & 7.1 & 8.7 & 1.6 \\
\hline & \multicolumn{5}{|c|}{ Sow feed consumption/piglet weaned } \\
\hline Observed difference & -1.9 & 0.1 & -0.6 & - & - \\
\hline$d^{o}, a a^{o}, d d^{o}$ & -2.0 & 0.1 & -0.8 & -1.3 & 0.10 \\
\hline$d^{o}, a a^{o}$ & -1.9 & 0.2 & -0.6 & -1.1 & 0.03 \\
\hline$d^{o}, d d^{o}$ & -2.0 & -0.8 & -0.8 & -1.3 & 0.40 \\
\hline$d^{o}$ & -2.0 & -1.4 & -1.0 & -1.9 & 0.80 \\
\hline
\end{tabular}

${ }^{1}$ Nonadditive effects included in the model; $d^{o}, a a^{o}, d d^{o}=$ direct dominance, additive $\times$ additive and dominance $\times$ dominance epistatic effects, respectively; ${ }^{2} \bar{P}, \overline{F_{1}}, \overline{F_{2}}, \overline{B C}$, $\overline{R C}=$ average performance of purebred, $F_{1}, F_{2}$, backcross and rotational cross genotypes, respectively; $|\overrightarrow{\mathrm{Bias}}|=$ average absolute deviation between predicted and observed values.

Finally, the large differences observed between $F_{2}$ and backcross sows differing only in their dam's genotype $(\mathrm{LW} \times \mathrm{MS} v s \mathrm{MS} \times \mathrm{LW})$ is not taken into account by standard models for crossbreeding. These differences may result from chance, but may also reflect true variations due to genetic effects not accounted for in the model. One possible hypothesis would be the existence of variation due to mitochondrial genes. Mitochondrial DNA in known to be maternally inherited in animals (see for instance Hayashi et al, 1978; or Gyllensten et al, 1985). Hence, differences in 
mitochondrial gene effects between MS and LW would generate variations due to the breed of the maternal ancestor similar to those observed in the present study. Including the effect of mitochondrial genes in the model would lead to some changes in estimates of crossbreeding parameters, as shown in table VIII. The main changes concern grand-maternal and, to a lesser extent, maternal breed effects. Direct breed and nonadditive effects remain unaffected. 'Mitochondrial' effects appear as highly significant and in favour of MS for litter size. Their influence on litter weights is less important and due to differences in prolificacy. However, these significant estimates cannot be regarded as a proof of the presence of mitochondrial gene effects. Other hypotheses, such as the existence of genomic imprinting, can be proposed to explain the observed differences, even if the way such effects would act is not as clear as hereabove.

\section{CONCLUSION}

The present study clearly shows the possibilities and limits to the use of complex genetic models for heterosis in pigs. Significant epistatic effects were found, thus showing that a simple dominance model for heterosis cannot always adequately predict the performance of advanced generations of crosses. However, epistatic effects in farm animals can only be estimated with a limited accuracy at a reasonable cost. As a consequence, predictions based on these parameters should be used cautiously, after looking at the impact of this uncertainty on the evaluation of crossbreeding schemes through sensitivity analyses.

\section{ACKNOWLEDGMENTS}

I thank the anonymous referees for their helpful suggestions and comments on the manuscript.

\section{REFERENCES}

Bidanel JP (1988) Bases zootechniques et génétiques de l'utilisation en élevage intensif des races prolifiques chinoises - cas du porc Meishan. Doctoral thesis, Institut National Agronomique Paris-Grignon, France, 194 p

Bidanel JP, Caritez JC, Legault C (1989) Estimation of crossbreeding parameters between Large White and Meishan porcine breeds. 1. Reproductive performance. Genet Sel Evol 21, 507-526

Bidanel JP, Caritez JC, Legault C (1990) Estimation of crossbreeding parameters between Large White and Meishan porcine breeds. 2. Growth before weaning and growth of females during the growing and reproduction periods. Genet Sel Evol 22, $431-445$

Buchanan DS (1987) The crossbred sire: experimental results for swine. J Anim Sci $65,117-127$

Cockerham CC (1954) An extension of the concept of partitioning hereditary variance for analysis of covariances among relatives when epistatic is present. Genetics 39, 859-882 


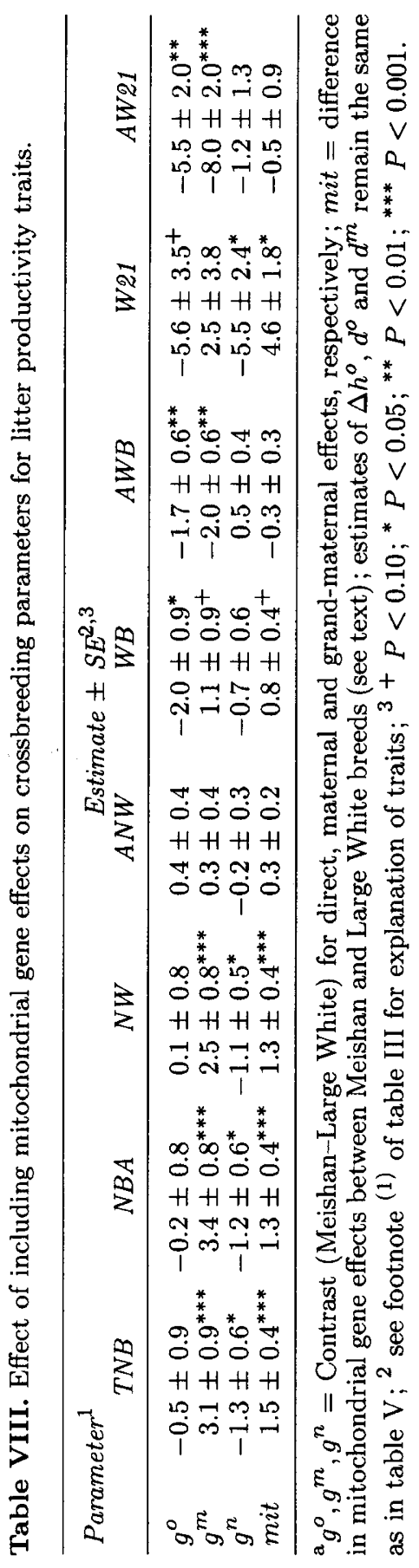


Dickerson GE (1969) Experimental approaches in utilising breed resources. Anim Breed Abstr 37, 191-202

Dickerson GE (1973) Inbreeding and heterosis in animals. In: Proc Anim Breeding Genet Symp in Honor of Dr JL Luch Am Soc Anim Sci Dairy Sci Assoc, Champaign, IL 54-77

Dillard EU, Rodriguez O, Robinson OW (1980) Estimation of additive and nonadditive direct and maternal genetic effects from crossbreeding beef cattle. $J$ Anim Sci 50, 653-663

Eisen EJ (1989) Genetic models to predict crossbred performance: a review. Rev Brasil Genet 12, (suppl-3), 13-26

Ericson K, Danell B (1986) Crossbreeding effects between two Swedish dairy breeds for production and reproduction traits. In: 37th Ann Meet EAAP, Commission on Cattle Production. Hungary, September 1986, $20 \mathrm{p}$

Fairfull RW, Gowe RS, Nagai J (1987) Dominance and epistasis in heterosis of White Leghorn strain crosses. Can J Anim Sci 67, 663-680

Fimland E (1983) Methods of estimating the effects of heterosis. Z Tierzüchtg Züchtgsbiol 100, 3-8

France J, Thornley JHM (1984) Mathematical Models in Agriculture. Butterworths, Boston, MA

Groeneveld E, Kovac M (1990) A generalized computing procedure for setting up and solving mixed linear models. J Dairy Sci 73, 513-531

Gyllensten U, Wharton D, Wilson AC (1985) Maternal inheritance of mitochondrial ${ }^{*}$ DNA during backcrossing of two species of mice. J Hered 76, 321-324

Hagger C (1986) Genetic effects of heterosis in $F_{1}$ and backcrosses of inbred lines of White Leghorns. J Anim Breed Genet 103, 26-32

Hagger C (1989) Genetic effects estimated from crosses and backcrosses of two related lines of White Leghorn chickens. J Anim Breed Genet 106, 241-248

Hayashi J, Yonekawa H, Gotoh O, Watanabe J, Tagashira Y (1978) Strictly maternal inheritance of rat mitochondrial DNA. Biochem Biophys Res Commun 83, 1032-1038

Henderson CR (1984) Applications of Linear Models in Animal Breeding. University of Guelph, Guelph, Ontario, Canada

Hill WG (1982) Dominance and epistasis as components of heterosis. $Z$ Tierzüchtg Züchtgsbiol 99, 161-168

Kennedy BW, Quinton M (1987) A note on the effects of health environment on heterosis for growth rate in pigs. Anim Prod 44, 443-445

Kinghorn B (1990) The expression of recombination loss in quantitative traits. Z Tierzüchtg Züchtgsbiol 97, 138-143

Kinghorn B (1982) Genetic effects in crossbreeding. I. Models of merit. Z Tierzüchtg Züchtgsbiol 99, 59-68

Kinghorn B (1983) Genetic effects in crossbreeding. III. Epistatic loss in crossbred mice. Z Tierzüchtg Züchtgsbiol 100, 209-222

Kinghorn B (1987) The nature of 2 locus epistatic interactions in animals: evidence from Sewall Wright's guinea-pig data. Theor Appl Genet 73, 595-604

Kinghorn BP, Vercoe PE (1989) The effect of using the wrong genetic model to predict the merit of crossbred genotypes. Anim Prod 49, 209-216 
Koch RM, Dickerson GE, Cundiff LV, Gregory KE (1985) Heterosis retained in advanced generations of crosses among Angus and Hereford cattle. J Anim Sci 60, $1117-1132$

Komender P, Hoeschele I (1989) Use of mixed-model methodology to improve estimation of crossbreeding parameters. Livest Prod Sci 21, 101-113

Legault C, Caritez JC (1983) L'expérimentation sur le porc chinois en France. I. Performances de reproduction en race pure et en croisement. Genet Sel Evol 15, 225-240

McGloughlin P (1980) The relationships between heterozygosity and heterosis in reproductive traits in mice. Anim Prod 30, 69-77

Meyer K (1988) DFREML a set of programs to estimate variance components under an individual animal model. J Dairy Sci 71 (suppl 2), 33-34 (abstr)

Meyer K (1989) Restricted maximum likelihood to estimate variance components for animal models with several random effects using a derivative-free algorithm. Genet Sel Evol 21, 317-340

Patterson HD, Thompson R (1971) Recovery of inter-block information when block sizes are unequal. Biometrika 58, 545-554

Pedersen J, Christensen LG (1989) Heterosis for milk production traits by crossing Red Danish, Finnish Ayrshire and Holstein - Friesian cattle. Livest Prod Sci 23, 253-266

Robinson OW, Mc Daniel BT, Rincon EJ (1981) Estimation of direct and maternal additive and heterotic effects from crossbreeding experiments in animals. J Anim Sci $52,44-50$

Sedcole JR (1981) A review of the theories of heterosis. Egypt J Genet Cytol 10, 117-146

Sheridan AK (1981) Crossbreeding and heterosis. Anim Breed Abstr 49, 131-144

Syrstad O (1988) Dairy cattle cross-breeding in the tropics: performance of secondary cross-bred populations. Livest Prod Sci 23, 97-106

Willham RL, Pollak E (1985) Theory of heterosis. J Dairy Sci 68, 2411-2417 